\title{
Subcutaneous adrenaline versus terbutaline in the treatment of acute severe asthma
}

\author{
M A SPITERI, A B MILLAR, D PAVIA, S W CLARKE \\ From the Department of Thoracic Medicine, Royal Free Hospital, London
}

ABSTRACT Subcutaneous adrenaline and terbutaline have been compared in a double blind study of 20 patients with acute severe asthma presenting to an accident and emergency department. Ten patients received adrenaline $0.5 \mathrm{mg}(0.5 \mathrm{ml})$ and 10 terbutaline $0.5 \mathrm{mg}(0.5 \mathrm{ml})$ subcutaneously. Further treatment with nebulised salbutamol $(5 \mathrm{mg})$, hydrocortisone $(200 \mathrm{mg})$, and aminophylline $(0.9 \mathrm{mg} / \mathrm{kg} /$ hour $)$ was started 15 minutes later. All patients reported a reduction in chest tightness within three minutes of receiving both adrenaline and terbutaline and reported no adverse effects. Mean baseline values of peak expiratory flow (PEF) and forced expiratory volume in one second $\left(\mathrm{FEV}_{1}\right)$ did not differ significantly between the adrenaline group $\left(130 \mathrm{l} \mathrm{min}^{-1}\right.$ and $\left.0.83 \mathrm{l}\right)$ and the terbutaline group (111 $\mathrm{min}^{-1}$ and 0.631$)$. After administration of adrenaline PEF had increased by $21 \%$ and $\mathrm{FEV}_{1}$ by $40 \%$ five minutes after the injection, and by $35 \%$ and $64 \%$ at 15 minutes. Terbutaline caused a $23 \%$ increase in PEF and a $37 \%$ increase in FEV 1 at five minutes, and a $40 \%$ and

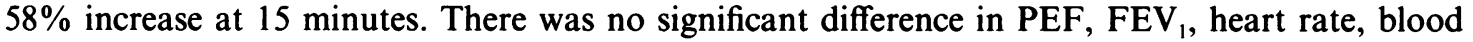
pressure, or pulsus paradoxus between the two groups at any time. Continuous electrocardiographic recording showed no abnormalities in either group. Thus in this study subcutaneous adrenaline $(0.5 \mathrm{mg})$ and terbutaline $(0.5 \mathrm{mg})$ produced effective rapid bronchodilatation without serious side effects.

\begin{abstract}
About 1500 patients continue to die from asthma each year in England and Wales,' despite self referral to hospital and intensive conventional treatment. Many factors are responsible for this, but one major problem is that severe attacks may start abruptly, often late at night or in the early morning. ${ }^{2-5}$ Our study was stimulated by the death of two young asthmatic women ${ }^{6}$ who were known to be "at risk" and for whom we had taken every precaution. Both had had abrupt attacks of asthma, developing within minutes and not responding to pressurised aerosol bronchodilators. Both died despite urgent hospital admission.

There are few reports ${ }^{267}$ supporting the use of self administration of parenteral adrenaline or selective $\beta_{2}$ adrenergic drugs in acute asthmatic attacks. Adrenaline appears to have lost favour ${ }^{8}$ because of the fear of adverse effects such as tachycardia, ventricular ectopic beats, hypertension, pulmonary oedema, tremor, sweating, and headaches, and even death. ${ }^{9-11}$ A closer look at these reports shows that most do not cite the original papers and most of the adverse effects quoted stem from early observations of adrenaline in status
\end{abstract}

Accepted 21 September 1987 asthmaticus, when high doses-such as 4-10 mg (4-10 $\mathrm{ml}$ of 1:1000) - of adrenaline were given. ${ }^{1213}$

We therefore designed a study to compare the efficacy and safety of subcutaneous adrenaline and terbutaline as first line treatment for patients with acute severe attacks of asthma presenting to the accident and emergency department. Permission for the study was obtained from the ethical practice subcommittee, and informed consent was obtained from every patient.

\section{Methods}

\section{PATIENTS}

Twenty patients aged 16-65 years were enrolled in the study (table 1). The mean (SEM) age for the adrenaline group was $31(2 \cdot 8)$ and for the terbutaline group $34(4 \cdot 2)$ years. Twelve were women (six in each group). All patients had an established history of asthma, for which they were receiving longstanding or intermittent bronchodilator treatment.

\section{SELECTION CRITERIA}

All our patients had to fulfill the following clinical and physiological criteria ${ }^{14}$ : tachypnoea at rest $(\geqslant 25$ 
Table 1 Details of patients receiving subcutaneous adrenaline or terbutaline

\begin{tabular}{|c|c|c|c|c|c|c|c|c|c|c|}
\hline Patient No: & 1 & 2 & 3 & 4 & 5 & 6 & 7 & 8 & 9 & 10 \\
\hline \multicolumn{11}{|l|}{ Terbutaline group } \\
\hline Age (y) & 19 & 37 & 38 & 34 & 33 & 48 & 30 & 16 & 25 & 64 \\
\hline Sex & & $\mathbf{F}$ & $\mathbf{M}$ & $\mathbf{F}$ & $\mathbf{M}$ & $\mathbf{M}$ & $\mathbf{F}$ & $\mathbf{F}$ & $\mathbf{M}$ & F \\
\hline Time of presentation (h) & 4.00 & 6.00 & 21.00 & 10.00 & 18.00 & 4.00 & 1.00 & 1.00 & 11.00 & 18.00 \\
\hline \multicolumn{11}{|l|}{ Baseline } \\
\hline PEF (1 min ') & 60 & 70 & 170 & 110 & 80 & 60 & 125 & 90 & 95 & 80 \\
\hline \multicolumn{10}{|l|}{ Adrenaline group } & 0.50 \\
\hline Age $(y)$ & 33 & 18 & 42 & 36 & 40 & 23 & 20 & 33 & 41 & 22 \\
\hline Sex & $\mathbf{M}$ & $\mathbf{M}$ & $\mathbf{F}$ & $\mathbf{F}$ & $\mathbf{F}$ & $\mathbf{M}$ & $\mathbf{F}$ & $\mathbf{M}$ & $\mathbf{F}$ & $\mathrm{F}$ \\
\hline Time of presentation (h) & 12.00 & 18.00 & 3.00 & 4.00 & 22.00 & 7.00 & 9.00 & 3.00 & 17.00 & 21.00 \\
\hline \multicolumn{11}{|l|}{ Baseline } \\
\hline PEF (1 min ') & 100 & 140 & 60 & 100 & 160 & 160 & 60 & 120 & 60 & 60 \\
\hline $\mathrm{FEV}_{1}(\mathrm{l})$ & 0.35 & 0.50 & 0.70 & 0.40 & 0.80 & 0.60 & 0.50 & 0.50 & 0.30 & 0.40 \\
\hline
\end{tabular}

PEF-peak expiratory flow; S-salbutamol; T-terbutaline; B-beclomethasone; A-aminophylline; 0-none.

breaths/min), sinus tachycardia ( $\geqslant 110$ beats/min), and pulsus paradoxus ( $\geqslant 10 \mathrm{~mm} \mathrm{Hg}$ ). All had symptoms of breathlessness and wheezing, which had increased rapidly and were refractory to increasing use of their normal medication. Patients with cardiovascular or cardiac disease (including hypertension) were excluded. Use of additional inhaled or oral medication did not preclude admission to the trial but full details were recorded.

\section{TREATMENT BEFORE ADMISSION}

The maintenance treatment of each patient during the week before admission is outlined in table 1. One patient who had not registered with a general practitioner after moving house was receiving no medication. The other 19 patients had used their pressurised aerosol bronchodilator on average three to four times on their way to hospital; six had used terbutaline (750 $1500 \mu \mathrm{g})$ and 13 salbutamol $(600-800 \mu \mathrm{g})$. None of the patients had taken any other additional treatment and none had received nebulised bronchodilators or parenteral therapy before or on arrival at hospital. No patient was being treated with systemic corticosteroids. Sixteen patients were brought to hospital by the emergency ambulance service; four were brought by relatives.

\section{PROCEDURE}

The initial assessment included measurement of heart rate, blood pressure, pulsus paradoxus, peak expiratory flow (PEF), forced expiratory volume in one second $\left(\mathrm{FEV}_{1}\right)$, and forced vital capacity $(\mathrm{FVC})$. Then adrenaline $0.5 \mathrm{mg}$ or terbutaline $0.5 \mathrm{mg}$ was administered double blind from coded ampoules as a slow subcutaneous injection over one minute from an insulin syringe. The patient's electrocardiogram was monitored throughout this time and for the succeeding 45 minutes with an oscilloscope, and a continuous record was obtained on magnetic tape for future analysis. Baseline measurements were repeated five and 15 minutes after the injection. At 15 minutes conventional treatment was started. Each patient was given nebulised salbutamol $5 \mathrm{mg}$ (in $1 \mathrm{ml}$ ) diluted in $3 \mathrm{ml}$ normal saline and an intravenous infusion of hydrocortisone $200 \mathrm{mg}$ and aminophylline $0.9 \mathrm{mg} / \mathrm{kg}$ / $\mathrm{h}$ in $500 \mathrm{ml} 5 \%$ dextrose over six hours. Measurements were repeated at 30 and 45 minutes. An experienced physician was in attendance throughout each study.

STATISTICAL ANALYSIS

Wilcoxon's rank sum test for paired and unpaired data was used and values were considered to be significantly different if $p \leqslant 0.05$.

\section{Results}

On admission to hospital all patients had a respiratory rate of 25-30 breaths/min, sinus tachycardia of more than 110 beats/min and pulsus paradoxus in excess of $10 \mathrm{~mm} \mathrm{Hg}$.

\section{PULMONARY FUNCTION MEASUREMENTS}

There was no significant difference in mean baseline PEF, FEV ${ }_{1}$, or FVC between the two groups (table 2). There was an increase in PEF, FEV , and FVC following both adrenaline and terbutaline five and 15 minutes after injection (table 2, figure), with no significant difference between drugs. Further 0 improvement in spirometric measurements was seen 30 and 45 minutes after nebulised salbutamol and intravenous aminophylline and hydrocortisone, again with no significant difference between groups.

\section{CARDIOVASCULAR MEASUREMENTS}

Baseline values of heart rate and blood pressure did not differ significantly between the two groups, nor 
Table 2 Pulmonary function, heart rate, and blood pressure (mean (SEM) values) at various points during the study

\begin{tabular}{|c|c|c|c|c|c|}
\hline & \multirow{2}{*}{$\begin{array}{l}\text { At time of } \\
\text { treatment }\end{array}$} & \multicolumn{4}{|c|}{ Minutes after treatment } \\
\hline & & 5 & 15 & 30 & 45 \\
\hline $\begin{array}{l}\text { Adrenaline group } \\
\text { PEF (l min }) \\
\text { FEV }(1) \\
\text { FVC (l) } \\
\text { Heart rate (beats } / \mathrm{min})\end{array}$ & $\begin{array}{l}110(19) \\
0 \cdot 83(0 \cdot 19) \\
1 \cdot 32(0 \cdot 24) \\
112(8 \cdot 2)\end{array}$ & $\begin{array}{l}157(25) \\
1 \cdot 17(0 \cdot 27) \\
1 \cdot 80(0 \cdot 32) \\
117(5 \cdot 4)\end{array}$ & $\begin{array}{l}174(33 \cdot 9) \\
1.35(0.37) \\
1.94(0.43) \\
112(5.4)\end{array}$ & $\begin{array}{l}240(29) \\
1.9(0.4) \\
2 \cdot 44(0.4) \\
114(5 \cdot 0)\end{array}$ & $\begin{array}{l}256(30) \\
2 \cdot 06(0.4) \\
2 \cdot 71(0.36) \\
111(6 \cdot 0)\end{array}$ \\
\hline $\begin{array}{l}\text { Blood pressure (mm Hg) } \\
\text { systolic } \\
\text { diastolic } \\
\text { Terbutaline group }\end{array}$ & $\begin{array}{r}124(3 \cdot 7) \\
82(2 \cdot 0)\end{array}$ & $\begin{array}{r}123(3 \cdot 4) \\
78(2 \cdot 0)\end{array}$ & $\begin{array}{r}119(3 \cdot 1) \\
76(3 \cdot 4)\end{array}$ & $\begin{array}{r}119(2 \cdot 7) \\
74(3 \cdot 7)\end{array}$ & $\begin{array}{r}119(2 \cdot 7) \\
73(3 \cdot 0)\end{array}$ \\
\hline $\begin{array}{l}\text { PEF (l min } \\
\text { FEV } 1 \text { (l) } \\
\text { FVC (l) } \\
\text { Heart rate (beats } / \mathrm{min}) \\
\text { Blood pressure }(\mathrm{mm} \mathrm{Hg})\end{array}$ & $\begin{array}{c}100(13) \\
0.63(0.05) \\
1 \cdot 19(0 \cdot 16) \\
122(4 \cdot 4)\end{array}$ & $\begin{array}{c}134(11) \\
0 \cdot 86(0 \cdot 09) \\
1 \cdot 57(0 \cdot 21) \\
120(3 \cdot 5)\end{array}$ & $\begin{array}{c}153(19 \cdot 7) \\
1 \cdot 0(0 \cdot 13) \\
1.97(0 \cdot 23) \\
114(6 \cdot 0)\end{array}$ & $\begin{array}{l}197(15) \\
1 \cdot 32(0 \cdot 16) \\
2 \cdot 36(0 \cdot 3) \\
119(6 \cdot 0)\end{array}$ & $\begin{array}{l}214(18) \\
1 \cdot 37(0 \cdot 19) \\
2 \cdot 56(0 \cdot 34) \\
116(51)\end{array}$ \\
\hline $\begin{array}{l}\text { systolic } \\
\text { diasystolic }\end{array}$ & $\begin{aligned} 124(2 \cdot 2) \\
78(2 \cdot 6)\end{aligned}$ & $\begin{array}{r}122(3 \cdot 3) \\
83(2 \cdot 6)\end{array}$ & $\begin{array}{r}118(3 \cdot 6) \\
74(2 \cdot 2)\end{array}$ & $\begin{array}{r}120(3 \cdot 0) \\
75(3 \cdot 1)\end{array}$ & $\begin{array}{r}119(3 \cdot 1) \\
74(3 \cdot 2)\end{array}$ \\
\hline
\end{tabular}

PEF-peak expiratory flow; FVC-forced vital capacity.

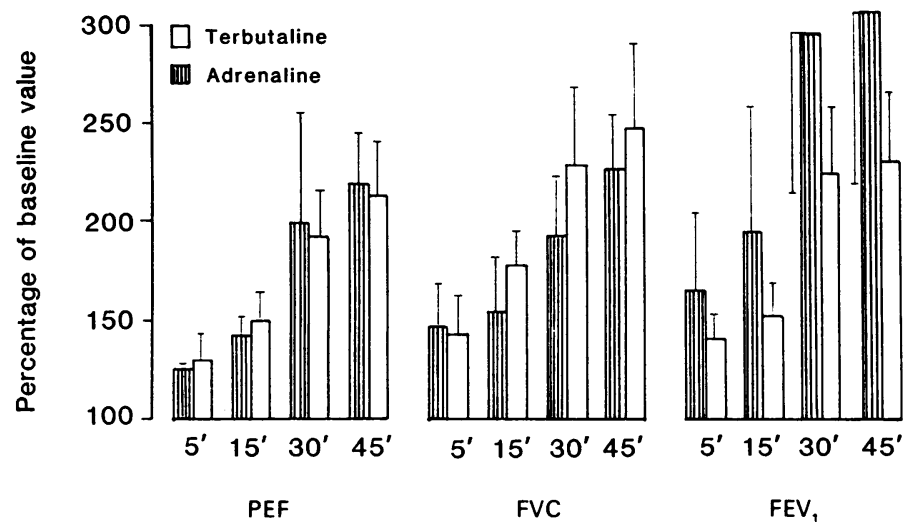

Effect of subcutaneous adrenaline and terbutaline on pulmonary function at five and 15 minutes and the additional effect of combined salbutamol (inhaled) and hydrocortisone and aminophylline (intravenous) treatment at 30 and 40 minutes. was there any significant increase in either measurement after adrenaline or terbutaline or after conventional treatment (table 2). Mean pulsus paradoxus was $15 \mathrm{~mm} \mathrm{Hg}$ (range $10-20 \mathrm{~mm} \mathrm{Hg}$ ) at the start of the study period, and this decreased significantly in each group after treatment, with no significant difference between adrenaline and terbutaline. The electrocardiograms showed no abnormalities other than sinus tachycardia on entry and throughout the study period.

\section{Discussion}

In 1977 Crompton ${ }^{15}$ discussed in detail the difficulties of carrying out clinical trials in patients with severe asthma and the problem of recruiting suitable patients before they had received conventional emergency treatment. We tried to ensure that every patient with acute severe asthma presenting to the accident and emergency department at any time of day would be referred for the study before being given nebulised or intravenous treatment. Placebo control was not included as all our subjects had acute severe asthma that required immediate relief; without a placebo we cannot be sure that all of the response seen after administration of adrenaline and terbutaline was due to the drugs, but the rapid subjective and objective improvement that followed the two drugs suggests that most if not all of the response was produced by the drugs.

We found that $0.5 \mathrm{mg}$ adrenaline given subcutaneously was as effective as $0.5 \mathrm{mg}$ subcutaneous terbutaline, and neither caused side effects in these patients. Subjective relief was noted within a mean time of three minutes from the injection, and this was reflected by improvement in pulmonary function 
measurements at five and 15 minutes. No adverse effects were noted with either drug at any time during the treatment. Less controlled clinical studies, without electrocardiographic monitoring, ${ }^{76-19}$ have shown no significant difference in bronchodilatation between parenteral adrenaline and terbutaline, and none has reported appreciable side effects. In this study further bronchodilatation occurred after inhalation of nebulised salbutamol and intravenous infusion of hydrocortisone and aminophylline. This has been observed with combined treatment previously, ${ }^{20}$ but possibly some of the additional improvement reflects the continuing action of subcutaneous adrenaline (maximum effect 30 minutes $^{12}$ ) or terbutaline (maximum effect $30-60$ minutes ${ }^{21}$ ).

Barger and Dale in $1910^{22}$ initiated the use of subcutaneous adrenaline for patients with acute asthma. Adrenaline may cause bronchodilatation through $\beta$ adrenoceptor agonism ${ }^{23}$ and via its $\alpha$ adrenergic action, producing decongestion of the bronchial mucosa. ${ }^{24}$ Adverse reports of anxiety, tremor, hypertension, palpitations, and cardiac arrhythmias and even death ${ }^{9-11}$ have also been attributed to $\alpha$ and $\beta$ adrenergic stimulation. Having checked these reports we believe that side effects may have been overemphasised, since they have often been associated with the use of massive doses of adrenaline, fast administration, and inadvertent intravenous injection. ${ }^{12}$ Side effects such as palpitations and tremor with smaller doses $(0.5 \mathrm{mg})$ of the drug have been minimal and have not been considered to be a problem by the patient in view of the quick and complete relief from asthma. ${ }^{2526}$

Traditionally, caution is urged in the use of adrenaline or $\beta$ adrenoceptor agonists in the elderly. When subcutaneous adrenaline $0.5 \mathrm{mg}$ was given to 100 asthmatic patients aged $50-80$ years and 25 young asthmatic patients aged 23-37 years widespread electrocardiographic changes were seen in over half the elderly patients but in only one of the young patients. Among the elderly patients 27 had angina, 13 hypertension, and nine cardiomegaly. ${ }^{27}$

Although drugs such as terbutaline and salbutamol are $\beta_{2}$ selective, they are not free of adverse effectssome effects indeed, such as tachycardia and tremor, being similar to those seen with adrenaline. ${ }^{17}$ In some studies heart rate changes with terbutaline have exceeded those that followed adrenaline,$^{28}$ and this was for the same amount of bronchodilatation in one study of asthmatic patients.' Dose-response curves for the two drugs have not, however, been compared and bronchodilator equivalence has not been established.

In conclusion, we found that both adrenaline and terbutaline $(0.5 \mathrm{mg})$ given subcutaneously gave rapid and effective bronchodilatation in patients with acute severe asthma with no important side effects. The response was rapid, occurring within three minutes.
Subcutaneous administration of either drug by self administration may be of value to patients prone to abrupt attacks of asthma. Further work is needed but, on the basis of our results and review of the published reports, we believe that subcutaneous administration of both terbutaline and adrenaline is less hazardous than hitherto believed.

We are grateful to Drs D Wynn-Mackenzie, P Jenkins, and $\mathrm{O}$ Corrado for their initial help in the study.

\section{References}

1 Stableforth D. Death from asthma. Thorax 1983;38:8015.

2 British Thoracic Association. Death from asthma in two regions of England. Br Med J 1982;285:1251-5.

3 Cochrane GM, Clarke TJH. A survey of asthma mortality in patients aged 35-64 in Greater London in 1971. Thorax 1975;30:300-5.

4 Hetzel MR, Clark TJH, Branthwaite MA. Asthma: analysis of sudden deaths and ventricular arrests in hospital. Br Med J 1977;i:808-11.

5 Anonymous. Fatal asthma [Editorial]. Lancet 1979;ii:337-8.

6 Bateman JRM, Clarke SW. Sudden death in asthma Thorax 1979;34:40-4.

7 Smith PR, Heurich AE, Leffler CT, Henis MJ, Lyons HA. A comparative study of subcutaneously administered terbutaline and epinephrine in the treatment of acute bronchial asthma. Chest 1977;71:129-34.

8 Anonymous. Management of severe acute asthma [Editoral]. Brit Med J 1978;i:873-4.

9 Greenburg MJ. Isoprenaline in myocardial failure [letter]. Lancet 1965;ii:442.

10 Goodman LS, Gilman A. The pharmacological basis of therapeutics. 5th ed. New York: MacMillan Publishing Company 1975:483-93.

11 Paterson JW, Woolcock AJ, Shenfield GM. Bronchodilator drugs. Am Rev Respir Dis 1979;120:1149.

12 Broom B. Adrenaline and status asthmatics. Lancet 1961;ii: 1174.

13 Freedman BJ. Adrenaline in status asthmaticus. Lancet 1955;ii:575.

14 Jones E Sherwood. The recognition and management of acute severe asthma. In: Bellingham AJ, ed. Advanced Medicine, 16. Tunbridge Wells: Pitman Medical, N 1980:9.

15 Crompton GK. Special problems of clinical trials in status asthmaticus. Br J Dis Chest 1977;71:242-4.

16 Rossing TH, Fanta CH, Goldstein DH, et al. Emergency therapy of asthma: comparison of the acute effects of parenteral and inhaled sympathomimetics and infused aminophylline. Am Rev Respir Dis 1980;122:365-71.

17 Tinkleman DG, Vanderpool GE, Carroll MS, et al. Comparison of nebulised terbutaline and subcutaneous epinephrine in the treatment of acute asthma. Ann Allergy 1983;50:398-401.

18 Johansen S. Clinical comparison of intramuscular terbutaline and subcutaneous adrenaline in bronchial asthma. Eur J Clin Pharmacol 1974;7:163-7. 
19 Baughman RP, Ploysongsang Y, James W. A comparative study of aerosolized terbutaline and subcutaneously administered epinephrine in the treatment of acute bronchial asthma. Ann Allergy 1984;53:131-4.

20 Rossing TH, Fanta CH, McFadden ER. A controlled trial of the use of single versus combined drug therapy in the treatment of acute episodes of asthma. Am Rev Respir Dis 1981;123:190-4.

21 Van den Berg W, Leferin JG, Maes RAA, et al. The effects of oral and subcutaneous administration of terbutaline in asthmatic patients. Eur $J$ Respir Dis 1984;65(suppl 134):181-93.

22 Barger G, Dale HH. Chemical structure and sympathomimetic action of amines. J Physiol 1910;41:19.

23 Ben-Zvi Z, Lam C, Spohn WA, et al. An evaluation of repeated injections of epinephrine for the initial treatment of acute asthma. Am Rev Respir Dis 1983;127:101-5.
24 Gotz UP, Brandsetter RD, Mar DD. Bronchodilator effect of subcutaneous epinephrine in acute asthma. Ann Emerg Med 1981;10:518.

25 Karetzky MS. Acute asthma: the use of subcutaneous epinephrine in therapy. Ann Allergy 1980;44:12-4.

26 Kobayshi T, Seki T. Effects of small doses of adrenaline on healthy man. Jap J Pharmacol 1974;24:119.

27 Bendkowski B. Effects of adrenaline injections on ECG in elderly asthmatics. J Coll Gen Pract 1964;8:66-71.

28 Arner B, Bertler A, Karlesfors T, et al. Circulatory effects of orciprenaline, adrenaline and a new sympathomimetic $\beta$-receptor-stimulating agent, terbutaline, in normal human subjects. Acta Med Scand 1970;512: 25-32.

29 Joint Formulary Committee. Bronchodilators. British National Formulary 1986. London: British Medical Association and Pharmaceutical Society of Great Britain, 1986:107-9. 